\title{
Breast Cancer in Young Women under 40 years: Epidemiological, Clinical, Therapeutic and Prognostic Aspects in the Oncology and Radiotherapy Department of Marrakech; About 318 Cases
}

K. Mazouz , S. Elouarzzazi, Y. Bouchabaka, D. Nimbuna, Z. Kaitoni, A. Elmatlini, M. Laanigri, M. Saadoun, M. Raouah, H. Abourazeq, S. Barkich, H. Eddaoualline, H. Sami, S. Laatitioui, M. Darfaoui, I. Lalya, A. Elomrani, M. Khouchani

Département de Radiothérapie, CHU Mohammed VI, Marrakech

DOI: $10.36348 /$ sijog.2019.v02i12.004

| Received: 20.12.2019 | Accepted: 27.12.2019 | Published: 30.12.2019

*Corresponding author: Mazouz Khadija

\section{Abstract}

Introduction: Breast cancer in women, and especially in young women, represents a real public health issue given its frequency and severity. The objective of our study is to specify the epidemiological profile; anatomo-clinical; therapy and prognosis of breast cancer in young women. Methods: Descriptive retrospective study spread over a period of 5 years (2013-2017), collecting all the patients followed for breast cancer aged 40 years or less, within the cancer department of CHU Med VI in Marrakech. Results: The average age was 34.2 years (19-40 years). The average age at puberty was 12 years old ( 9 and 16 years old). Nulliparity was noted in $22 \%$ of the cases. Clinically, the T classification in the cases specified was: T1 $(n=48), T 2(n=128), T 3(n=52), T 4(n=42)$. Clinical lymph node involvement was found in $44 \%$ of the cases. Histologically, infiltrating ductal carcinoma was the most common $(n=283)$. SBR II grade was the most frequent with a rate of $66 \%$, Thirty Fifty percent of all patients had an over-expression of HER2, Sixtythree percent had lymph node invasion, including $42 \%$ with capsular rupture and $31 \%$ of patients were metastatic in appearance. Therapeutically, fifty patients had neo-adjuvant chemotherapy. The surgery was conservative in $66 \%$ of the cases. Adjuvant chemotherapy was sequential in $61 \%$ of the cases. 180 patients had adjuvant radiation therapy. Of the 96 patients with HER2 over expression, 82 received treatment with trastuzumab. Hormone therapy was prescribed in 156 patients or $49 \%$ of cases with expression of hormone receptors. In our series, the median follow-up was 8.1 months. The course was marked by a locoregional relapse in fifty-eight patients, and a metastatic relapse in sixty patients. Conclusion: Since screening in our country does not include young women, it would be interesting to reconsider its indications, especially given the growing frequency of this cancer in young women as well as its poor prognosis.

Keywords: Breast cancer / young woman / prognostic factors / treatment.

Copyright @ 2019: This is an open-access article distributed under the terms of the Creative Commons Attribution license which permits unrestricted use, distribution, and reproduction in any medium for non-commercial use (NonCommercial, or CC-BY-NC) provided the original author and source are credited.

\section{INTRODUCTION}

Breast cancer in women, and especially in young women, represents a real public health issue given its frequency and severity [1]. In Morocco, as in the world, its incidence continues to increase until currently becoming the first gyneco-mammary cancer in women. The definition of breast cancer in young women is not unequivocal. According to studies, a "young" woman corresponds to a woman under 35 years old, under 40 years old, or even just after menopause [2]; We will stick to the second definition. Its occurrence constitutes a dramatic event in the life of a woman; it is still badly felt and difficult to accept [3]. Especially in young women, the diagnosis of breast cancer is often unexpected and therefore delayed. According to the majority of authors, breast cancer in young women has its own epidemiological, diagnostic and also prognostic characteristics, going so far as to consider youth as a poor prognostic factor. The aim of our study is to describe the different epidemiological, clinical, anatomo-pathological, therapeutic and prognostic features of breast cancer in young women. 


\section{PATIENTS AND METHODS}

This is a descriptive retrospective epidemiological study, covering 318 cases of breast cancer in women under 40, collecting all patients followed for breast cancer aged 40 or less, within the service of oncology of CHU Med VI Marrakech, over a period of 5 years (2013-2017).

Clinical information was collected from clinical and technical patient files using an exploitation sheet. The study variants selected were age, personal and family history, consultation time, clinical characteristics and paraclinical, histological examination of the part and extension assessment. Thus all the patients were stratified according to the TNM classification.

The pre-therapeutic assessment included an interrogation, a clinical examination, an echomammography, a chest radiography, an abdominal ultrasound, a thoraco-abdomino-pelvin CT, a bone scan and sometimes a CA-15-3 assay. The hormone receptors $(\mathrm{RH})$, the research proto-oncogene HER-2 / neu, and the histopronostic grade of ScarffBloomRichardson (SBR), were specified in all the patients.

The management of these patients is validated during a multidisciplinary concertation meeting bringing together a gyneco obstetrician, an oncologist, a radiotherapist.

For operable non-metastatic tumors of size less than $3 \mathrm{~cm}$, conservative surgery was indicated, followed by radiotherapy on the breast and the supraclavicular area in the event of lymph node involvement at doses between 50 and $54 \mathrm{~Gy}$, with a boost of 14 to $16 \mathrm{~Gy}$ on the tumor bed (standard spreading spread: 1.8-2 Gy per session; 5 sessions / week) associated or not with adjuvant chemotherapy depending on the anatomopathological results. Those larger than $3 \mathrm{~cm}$ were often treated by radical Patey surgery followed by radiotherapy of the thoracic wall and the supraclavicular area at a dose of 50-54 Gy, and 6 to 8 courses of chemotherapy as adjuvant function of the anatomopathological report.

In the case of locally advanced tumors (T4), patients benefited from neoadjuvant chemotherapy followed by Patey surgery and locoregional radiotherapy.

The statistical study was carried out by the SPSS statistical computer program. The estimates of overall survival and disease-free survival were carried out according to the Kaplan Meier method.

\section{RESULTS \\ Epidemiological Criteria \\ During the study period (2013-2017), the oncology and radiotherapy department of the Mohammed VI CHU in Marrakech admitted 2,207 cases of breast cancer. Among these patients, 318 were aged 40 and under, representing a rate of $14.4 \%$ of the total number of patients with breast cancer during this period.}

Table-1: Distribution of the annual frequency of breast cancer in our series

\begin{tabular}{|l|l|l|l|}
\hline Year & Number of cases $\leq \mathbf{4 0}$ years & Numbre of cases & Percentage $(\boldsymbol{\%})$ \\
\hline 2013 & 47 & 432 & $10.87 \%$ \\
\hline 2014 & 52 & 407 & $12.77 \%$ \\
\hline 2015 & 54 & 409 & $13.2 \%$ \\
\hline 2016 & 90 & 526 & $17.11 \%$ \\
\hline 2017 & 75 & 434 & $17.28 \%$ \\
\hline Total & 318 & 2207 & $14.4 \%$ \\
\hline
\end{tabular}

The average age of the patients was 34.2 years with extremes of 19 and 40 years. The 36-40 age group was the most affected with a rate of $50 \%$.

As for risk factors; the age of the menarche was specified in 134 patients. 104 of them had a menarche at an age $>12$ years or $77.6 \%$ of cases, while only 30 patients had their early menarche at an age $\leq 12$ years or $22.4 \%$ of cases. Contraceptive use was specified in 258 patients. Thus, 136 of them confirmed taking oral contraceptives, or $52.7 \%$ of cases, for an average duration of 7 years with extremes of 6 months and 20 years. The age of first pregnancy in nonnulliparous patients $(88 \%)$ was specified in 96 women. He was 22 years old on average with extremes of 17 and 38 years old. Personal history of fibrocystic mastopathy was found in 5 patients or $1.6 \%$. Among the 318 patients, a family history of breast cancer was found in 42 patients or $13.2 \%$ of cases. In addition, we noted 1 case of endometrial cancer; 4 cases of ovarian cancer and 3 cases of cervical cancer.

\section{Clinical Criteria}

The delay between the appearance of the first symptoms and the date of the first consultation was specified in 286 patients. Thus, the average time was 7 months with extremes of 1 month and 5 years.

Breast cancer was discovered in $98 \%$ of cases by the patient herself by self-examination of a breast 
nodule, while only 5 cases were detected during a systematic medical examination, or $2 \%$. Bilateral damage was observed in 8 patients $(2.5 \%)$. The mean clinical nodule size was $5.5 \mathrm{~cm}$ with extremes of $1 \mathrm{~cm}$ and $10 \mathrm{~cm}$, fixed in 63 women or $41 \%$. Palpation of the lymph nodes made it possible to objectify the presence of axillary lymphadenopathy in $25 \%$ of the cases. The cT2N2M0 stages were predominant (48\%).

The ultrasound-mammography couple was performed in all the patients, and showed a predominance of the ACR5 stage; The MRI was performed in a single patient, she objectified a speculated image with calcifications. The multifocalities was observed in $20 \%$.

At the end of the extension assessment, 86 patients were immediately metastatic, i.e. $31 \%$ of the cases. The main site of metastasis was bone $(43 \%)$, followed by the liver $(28 \%)$, then the lungs and pleura $(23 \%)$, then the brain $(6 \%)$.

Table-2: Epidemiological an clinical caracteristics of patients

\begin{tabular}{|l|l|}
\hline Caracteristics & Numbre of patients $(\%)$ \\
\hline Singles $(\mathrm{n}=318)$ & $19 \%(\mathrm{n}=62)$ \\
\hline Nulligeste $(\mathrm{n}=318)$ & $22 \%(\mathrm{n}=70)$ \\
\hline Menarche less than 12 ans $(\mathrm{n}=134)$ & $22.4 \%(\mathrm{n}=30)$ \\
\hline Familly history $(\mathrm{n}=318)$ & $13.2 \%(\mathrm{n}=42)$ \\
\hline Tumora size (n $=318)$ & \\
T1 & $17 \%(\mathrm{n}=56)$ \\
T2 & $45.7 \%(\mathrm{n}=146)$ \\
T3 & $18.5 \%(\mathrm{n}=58)$ \\
T4 & $18.5 \%(\mathrm{n}=58)$ \\
\hline Clinical GG $(\mathrm{n}=318)$. & $25 \%(\mathrm{n}=80)$ \\
\hline
\end{tabular}

\section{Therapeutic Results}

The majority of patients received multimodal treatment combining conservative or radical surgery, radiotherapy and adjuvant or neoadjuvant chemotherapy.

On the therapeutic side, breast surgery was performed on 240 of our patients: it was radical (mastectomy with axillary dissection) in $66 \%$ of cases and conservative (tumerectomy with axillary dissection) in $34 \%$ of cases.

The sentinel node technique was performed in only one patient, and 2 patients benefited from breast reconstruction. The surgery was performed after neoadjuvant chemotherapy for locally advanced tumors in 56 patients.

In the anatomopathological study, non-specific invasive carcinoma was the most predominant with a rate of $89 \%$, followed by infiltrative lobular carcinoma (CLI) with a rate of $5.66 \%$. Grade SBR II was the most common at $66 \%$, followed by grade SBR III at $30 \%$. These estrogen (ER) and progesterone (RP) receptors were both positive in $65 \%$ of the cases, dissociated in $7 \%$ and negative in $28 \%$. $35 \%$ of all patients had overexpression of the HER2. The tumor emboli were positive in $76 \%$ of the cases. Three hundred and eight patients presented healthy margins of excision. $69 \%$ had a lymph node invasion $83 \%$ presented a capsular breach.

In the adjuvant setting, 191 patients benefited from external radiotherapy, and chemotherapy was indicated in 170 patients, ie $61 \%$ of the cases, while $20 \%$ received it as a neo-adjuvant, based on anthracyclines and taxanes in 6 or 8 courses. Hormone therapy was started in 156 patients; curative in 144 and palliative in the remaining 12, and consisted of administer tamoxifen-type antiestrogens in 142 patients and anti-estrogens with medical castration in 14 cases, with an average duration of taking 14.7 months (1 month and 5 years). Trastuzumab was indicated in $86 \%$ of cases.

In our series, the patients were followed until March 2019. The median follow-up was 8.1 months with extremes of 1 month and 7 years 3 months. 118 patients (37\% of all cases) had a relapse of their disease in the form of a locoregional recurrence (49\%), metastatic dissemination $(51 \%)$ or both. The mean time to relapse was 9.5 months. The number of patients who died was 82 or $25.7 \%$ of all patients, with an average survival time of 2.6 years and extremes ranging from 2 years to 4 years. 91 cases or $28.6 \%$ lost to follow-up and 145 are still alive $(45.6 \%)$. 
Table-3: Pathological characteristics of the patients

\begin{tabular}{|c|c|}
\hline Caracteristics & Number of patients (\%) \\
\hline $\begin{array}{lr}\text { Histological type } & (\mathrm{n}=318) \\
\text { ductal } & \text { carcinoma } \\
\text { Lobular } & \text { carcinoma } \\
\text { Athers } & \\
\end{array}$ & $\begin{array}{l}89 \%(\mathrm{n}=283) \\
6 \%(\mathrm{n}=19) \\
5 \%(\mathrm{n}=(16)\end{array}$ \\
\hline $\begin{array}{llrr}\text { Nuclear grades }(\mathrm{n}= & 318) \\
\text { Grade } & & & \text { I } \\
\text { Grade } & & & \text { II } \\
\text { Grade III } & & & \\
\end{array}$ & $\begin{array}{l}4 \%(n=13) \\
66 \%(n=210) \\
30 \%(n=95)\end{array}$ \\
\hline $\begin{array}{ll}\text { Hormons receptors }(n= & 318) \\
\text { RE+ } & \mathrm{RP}- \\
\mathrm{RE}- & \mathrm{RP}+ \\
\mathrm{RE}- & \mathrm{RP}- \\
\mathrm{RE}+ & \mathrm{RP}+ \\
\text { Non précisé } & \\
\end{array}$ & $\begin{array}{l}3 \%(n=10) \\
4 \%(n=13) \\
28 \%(n=90) \\
65 \%(205)\end{array}$ \\
\hline $\begin{array}{l}\text { overexpression HER2 }(n=274) \\
\text { HER2+ } \\
\text { HER2- }\end{array}$ & $\begin{array}{l}65 \%(n=178) \\
35 \%(n=96)\end{array}$ \\
\hline Tumor embolis $(n=200)$ & $76 \%(152)$ \\
\hline Intraductal Component $(\mathrm{n}=110)$ & $75 \%(n=82)$ \\
\hline
\end{tabular}

\section{DISCUSSION}

The age limit for defining breast cancer in young women is controversial; several series have defined a "young" woman as corresponding to a woman under $30,35,40,45$ years or simply not menopausal [14]. In our study, and as for the majority of the authors, the age limit of 40 years was fixed.

According to the GLOBOCAN 2018 database, which groups the incidences and mortality in 185 countries of 36 types of cancer; the most common type of cancer in women, in all regions, was breast cancer, accounting for 22 to $28 \%$ of new cases [5].

Nationally, 35.8\% of cases are recorded in GRAND CASABLANCA CANCER REGISTER The incidence of breast cancer in women increased continuously with age; a peak was recorded for the age class 55-59 reaching 197.3 per 100,000 women [6]; which is consistent with the data from our study where $85.6 \%$ of women with breast cancer were over 40 years of age; while patients aged 40 and under represented only $14.4 \%$.

The frequency of breast cancer in young women varies according to the authors. $6.6 \%$ in the United States (USA) according to Anders [7] and only $1.3 \%$ in Finland according to Liukkonen [8]. In Latin America, this frequency reaches $20 \%$ according to Villarreal-Garza [9].

In our study the frequency of breast cancer in young women was $14.4 \%$ which joins Bouzid's study [10] with a frequency of $11 \%$, while it was around $25.24 \%$ in the Boufettal study [4], and $7.4 \%$ in the series by C. Fleurier [11].
The average age of diagnosis of breast cancer was 34.2 years with extremes of 19 and 40 years, which is consistent with the data in the literature, or this average varies between 31 and 32 years [12]. The lowest age reported in the literature is 14 years [1].

The family history of breast cancer seems to be the essential risk factor for developing breast cancer at a young age $[13,14]$ indeed, it is, here, the transmission of a genetic mutation mainly at the level BRCA1 and BRCA2 genes responsible for the development of cancer from one generation to another [15]. In our study, the family history of breast cancer was found in $13.2 \%$ of cases, which is consistent with the data in the literature; moreover, in our series, no patient benefited from the search for the BRCA1 and BRCA2 genes seen on high cost. Other risk factors linked to the female genital life have been retained, mainly, early menarche and nulliparity $[12,16]$ because these women have been exposed to estrogen secretion for longer. In our study, the early menarche was objectified in $22.4 \%$ of the cases, the nulliparity in $22 \%$ which agrees with the other series.

In our series; clinical criteria did not present any particularity in young women, breast nodule was the most frequent reason for consultation with a rate of $87.7 \%$, which corresponds to other studies. The discovery is often late and the tumor size is larger compared to older women. The average clinical nodule size in our series was $5.5 \mathrm{~cm}$. Palpation of the lymph nodes made it possible to objectify the presence of axillary lymphadenopathy in $25 \%$ of the cases; $\mathrm{Ct} 2 \mathrm{n} 2 \mathrm{M} 0$ stages were predominant in $48 \%$ of the cases, which joins all the published series. The authors report a T2 frequency of $40 \%$ to $50 \%$ of cases $[3,4,17,10]$, 
and clinical lymph node involvement varied between 50 and $75 \%[1,4,10]$.

Exploring breast cancer is more difficult in young women [18]; Mammography was classically unsuccessful and must be coupled with Breast ultrasound according to several authors [3, 19] MRI is very important in this population of young women allowing a correct estimate of multifocal, bilateral cancers and recurrences [20]. This investigation was not carried out in our population due to lack of resources, and half of the patients initially presented ACR 5 lesions on mammography.

The diagnostic certainty of breast cancer is provided by histological examination. The distribution of histological types in young women does not differ from that observed in elderly women. Most authors [21] agree on the predominance of invasive carcinomas in young women as well as in elderly women. In our study infiltrating ductal carcinoma predominates with a rate of $89 \%$, joining the other series of Bouzid with a rate of $95 \%$ [10]; of boufettal with a rate of $73 \%$ [4], of C. Fleurier [11] with a rate of $91 \%$.

The high histo-prognostic grade and the high level of negative hormone receptors explain the aggressiveness of cancer in young women. According to the prospective American observational study POSH [22] evaluating the anatomopathological characteristics of 2,956 cases of breast cancer in women aged under 40, the study objectified the following characteristics: $58.9 \%$ of grade III tumors, a third of negative estrogen receptors and a quarter of Her2 overexpression which does not correspond to the results of our study where grade II was the most frequent with a rate of $66 \%$; estrogen (ER) and progesterone (RP) receptors were both positive in $65 \%$ of the cases.

Many authors agree that lymph node invasion is more frequently observed in young women and is around $50 \%$ in the majority of series $[3,10,11,22]$. We found a rate of $69 \%$, close to the bouzid series [10].

The indications for surgical treatment in young women do not differ from those in older women, VAN DE VELDE [23] and GENEVIEVE [24], compared radical surgery to conservative surgery in young women and found that not only the recurrence rate was three times lower in women treated with mastectomy, but that the survival rate was significantly higher in this category of patients. This is linked to unfavorable differences in stage and tumor biology in young women according to Matthews et al., [25]; but this should not lead to the exclusion of conservative surgery in this population. In our series $41 \%$ recurred after conservative treatment and $31 \%$ after a patty.

The main aim of radiotherapy is local control of the tumor. It reduces the risk of locoregional relapse by $70 \%$ and improves overall survival [26, 27]. Radiation therapy is systematic after conservative surgery, its beneficial effect has been mainly observed in young women [28]. Parietal irradiation after radical surgery is recommended for tumors larger than $20 \mathrm{~mm}$ (T2) in young women after sufficient negative axillary lymph node dissection [29].

The interest of chemotherapy is currently demonstrated in the treatment of breast cancer in young women; regardless of lymph node status and stage of the disease. An annual reduction of $29 \%$ in the risk of general mortality in patients under 40 was shown in the Oxford meta-analysis [30]. The efficacy of adjuvant HTC is greater in premenopausal women, hence the more frequent use of adjuvant chemotherapy in young women [31], in our series $61 \%$ of our patients received adjuvant chemotherapy. However, the advantage of herceptin in the adjuvant situation has been demonstrated for HER-2 + patients regardless of age [32]. Early menopause can be induced by chemotherapy. This risk must be explained to patients wishing to have pregnancies.

The hormone therapy currently recommended in young women is tamoxifen alone or associated with ovarian suppression; Anti-aromatases have no place. Tamoxifen given to young women prolongs survival and delays relapse, although its benefit is not as great as that obtained in postmenopausal women [33].

Local recurrences and metastases occur more often in young women than in older women [4, 34]. According to Rochefordiere et al., after five years, the relative risk of recurrence decreases less quickly in young women $[4,35]$.

In our series, locoregional relapses were $18 \%$ joining most of the Maghreb and Western series, and metastatic relapses were $19 \%$, a rate which joined the boufettal and flower series and which is lower than the other series $[4,10,11]$.

The 5-year survival rate is even lower when the age is young. The MOLNAR series [36] has objectified that survival in young women is much lower than in older patients. Thus, other series [36, 37] have found a correlation between young age and low survival rate.

In our series, the overall 3-year survival was $68 \%$ and the relapse-free survival at $59 \%$, which joins the Maghreb series: bouzid, and Boufettal $[4,10]$.

The factors most often retained in the literature as poor prognosis, are identical regardless of the age of diagnosis including, tumor size; lymph node involvement, histopronostic stage, hormone receptors, intracanal component (CIC) greater than $25 \%$. In young women, the poor prognosis for breast cancer is the 
advanced stage of diagnosis [38]. In our series, the presence of vascular emboli was identified in $76 \%$ of patients and CIC greater than $25 \%$ in $75 \%$ of cases.

\section{CONCLUSION}

Young age is often associated with anatomical-clinical and progressive parameters of poor prognosis, It is therefore necessary to adopt multidisciplinary management. It would be interesting to reconsider the indications for screening in our country as they do not include young women, as well as to encourage oncogenetic consultations in women at risk.

\section{REFERENCES}

1. Jmor, S., Al-Sayer, H., Heys, S. D., Payne, S., Miller, I., Ah-See, A., ... \& Eremin, O. (2002). Breast cancer in women aged 35 and under: prognosis and survival. Journal of the Royal College of Surgeons of Edinburgh, 47(5), 693-699.

2. Espié, M., \& Cottu, P. H. (2003). Cancer du sein de la femme jeune: problèmes et questions. Pathologie Biologie, 7(51), 391-392.

3. Foxcroft, L. M., Evans, E. B., \& Porter, A. J. (2004). The diagnosis of breast cancer in women younger than 40. The breast, 13(4), 297-306.

4. Boufettal, H., Noun, M., \& Samouh, N. (2010). Cancer du sein chez la femme jeune au Maroc. Cancer/Radiothérapie, 14(8), 698-703.

5. Bray, F., Ferlay, J., Soerjomataram, I., Siegel, R. L., Torre, L. A., \& Jemal, A. (2018). Global cancer statistics 2018: GLOBOCAN estimates of incidence and mortality worldwide for 36 cancers in 185 countries. CA: a cancer journal for clinicians, 68(6), 394-424.

6. Registre des cancer Region grand Casablanca Edition 2016.

7. Anders, C. K., Hsu, D. S., Broadwater, G., Acharya, C. R., Foekens, J. A., Zhang, Y., ... \& Nevins, J. R. (2008). Young age at diagnosis correlates with worse prognosis and defines a subset of breast cancers with shared patterns of gene expression. Journal of clinical oncology, 26(20), 3324-3330.

8. Liukkonen, S., Leidenius, M., Saarto, T., \& Sjöström-Mattson, J. (2011). Breast cancer in very young women. European Journal of Surgical Oncology (EJSO), 37(12), 1030-1037.

9. Villarreal-Garza, C., Aguila, C., MagallanesHoyos, M. C., Mohar, A., Bargalló, E., Meneses, A., ... \& Murillo, R. (2013). Breast cancer in young women in Latin America: an unmet, growing burden. The oncologist, 18 (Special Collection), 26-34.

10. Bouzid, N., Lahmar, R., Tebra, S., \& Bouaouina, N. (2013). Cancer du sein chez la femme jeune de moins de 35 ans en Tunisie: étude rétrospective à propos de 124 cas. Gynécologie Obstétrique \& Fertilité, 41(6), 356-360.
11. Fleurier, C., Pilloy, J., Chas, M., Cirier, J., Jourdan, M. L., Arbion, F., ... \& Ouldamer, L. (2018). Cancer du sein chez les patientes de moins de 40 ans: présentation et caractéristiques évolutives. Gynécologie Obstétrique Fertilité \& Sénologie, 46(2), 105-111.

12. Yankaskas, B. C. (2006). Epidemiology of breast cancer in young women. Breast disease, 23(1), 38.

13. Chan, A., Pintilie, M., Vallis, K., Girourd, C., \& Goss, P. (2000). Breast cancer in women $\leq 35$ years: review of 1002 cases from a single institution. Annals of oncology,11(10), 12551262.

14. Kothari, A. S., Beechey-Newman, N., D'Arrigo, C., Hanby, A. M., Ryder, K., Hamed, H., \& Fentiman, I. S. (2002). Breast carcinoma in women age 25 years or less. Cancer, 94(3), 606614.

15. Baretta, Z., Mocellin, S., Goldin, E., Olopade, O. I., \& Huo, D. (2016). Effect of BRCA germline mutations on breast cancer prognosis: a systematic review and metaanalysis. Medicine, 95(40):e4975.

16. Daraei, A., Izadi, P., Khorasani, G., Nafissi, N., Naghizadeh, M. M., Younosi, N., ... \& Saadatian, Z. (2019). Methylation of progesterone receptor isoform A promoter in normal breast tissue: An epigenetic link between early age at menarche and risk of breast cancer?.Journal of cellular biochemistry. 120(8):12393-12401.

17. De La Rochefordiere, A., Campana, F., Fenton, J., Vilcoq, J. R., Fourquet, A., Asselain, B., ... \& Magdelenat, H. (1993). Age as prognostic factor in premenopausal breast carcinoma. The Lancet, 341(8852), 1039-1043.

18. Johnstone, P. A., Moore, E. M., Carrillo, R., \& Goepfert, C. J. (2001). Yield of mammography in selected patients age $\leq 30$ years. Cancer: Interdisciplinary International Journal of the American Cancer Society, 91(6), 1075-1078.

19. Houssami, N., Irwig, L., Simpson, J. M., McKessar, M., Blome, S., \& Noakes, J. (2003). Sydney Breast Imaging Accuracy Study: comparative sensitivity and specificity of mammography and sonography in young women with symptoms. American Journal of Roentgenology, 180(4), 935-940.

20. Taourel, P., Thomassin, I., \& Tardivon, A. (2011). Indications actualisées de l'IRM du sein: synthèse du référentiel édité par The European Society of Breast Cancer Specialist (EUSOMA). Imagerie de la Femme, 21(4), 154-159.

21. Bharat, A., Aft, R. L., Gao, F., \& Margenthaler, J. A. (2009). Patient and tumor characteristics associated with increased mortality in young women ( $\leq 40$ years) with breast cancer. Journal of surgical oncology, 100(3), 248-251.

22. Kroman, N., Tutt, A., Jensen, M. B., Wohlfahrt, J., Mouridsen, H. T., Andersen, P. K., ... \& Ross, G. 
(2000). Factors influencing the effect of age on prognosis in breast cancer: population based studyCommentary: much still to learn about relations between tumour biology, prognosis, and treatment outcome in early breast cancer. Bmj, 320(7233), 474-479.

23. Van De Velde, C. J. H., Van Sprundel, T. C., van der Hage, J., \& van de Vijver, M. J. (2004). Mastectomy: the preferred treatment in young women?. EJC Supplements, 3(2), 66-67.

24. Coulombe, G., Tyldesley, S., Speers, C., Paltiel, C., Aquino-Parsons, C., Bernstein, V., ... \& Olivotto, I. A. (2007). Is mastectomy superior to breast-conserving treatment for young women?. International Journal of Radiation Oncology* Biology* Physics, 67(5), 1282-1290.

25. Di Nubila, B., Cassano, E., Urban, L. A., Fedele, P., Abbate, F., Maisonneuve, P., ... \& Bellomi, M. (2006). Radiological features and pathologicalbiological correlations in 348 women with breast cancer under 35 years old. The Breast, 15(6), 744753.

26. Whelan, T. J., Julian, J., Wright, J., Jadad, A. R., \& Levine, M. L. (2000). Does locoregional radiation therapy improve survival in breast cancer? A meta-analysis. Journal of Clinical Oncology, 18(6), 1220-1229.

27. Taghian, A. G., \& Powell, S. N. (1999). The role of radiation therapy for primary breast cancer. Surgical Clinics of North America, 79(5), 1091-1115.

28. Mansouri, H., Hassouni, K., Gaye, M., Benjaafar, N., \& Gueddari, B. E. (2001). Place de la radiothérapie post-opératoire dans le cancer du sein. Espérance médicale, 8(72), 265-267.

29. Ammar, C. B., Kochbati, L., Chraeit, N., Amrouche, A., Gargouri, W., Frikha, H., ... \& Maalej, M. (2008). L'irradiation pariétale est-elle justifiée après mastectomie et curage négatif?. Cancer/Radiothérapie, 12(2), 73-77.

30. Namer, M., Gligorov, J., \& Luporsi, E. (2007). Recommandations pour la pratique clinique de Saint Paul de Vence. Oncologie, 9(9), 593-644.

31. Prowell, T. M., \& Davidson, N. E. (2004). What is the role of ovarian ablation in the management of primary and metastatic breast cancer today?. The oncologist, 9(5), 507-517.

32. Tuma, R. S. (2005). Trastuzumab trials steal show at ASCO meeting. Journal of the National Cancer Institute, 97(12), 870-871.

33. Sonmezer, M., \& Oktay, K. (2006). Fertility preservation in young women undergoing breast cancer therapy. The Oncologist, 11(5), 422-434.

34. Tuma, R. S. (2005). Trastuzumab trials steal show at ASCO meeting. Journal of the National Cancer Institute, 97(12), 870-871.

35. De La Rochefordiere, A., Campana, F., Fenton, J., Vilcoq, J. R., Fourquet, A., Asselain, B., ... \& Magdelenat, H. (1993). Age as prognostic factor in premenopausal breast carcinoma. The Lancet, 341(8852), 1039-1043.

36. Yıldırım, E., Dalgıç, T., \& Berberoğlu, U. (2000). Prognostic significance of young age in breast cancer. Journal of surgical oncology, 74(4), 267272.

37. Touboul, E., Buffat, L., Belkacémi, Y., Lefranc, J. P., Uzan, S., Lhuillier, P., ... \& Pène, F. (1999). Local recurrences and distant metastases after breast-conserving surgery and radiation therapy for early breast cancer. International Journal of Radiation Oncology* Biology* Physics, 43(1), 2538.

38. Rapiti, G. (2004). Prognosis of breast cancer in young women: a population based study. Geneva cancer registry, department of gynecology and obstetrics, Geneva university, Switzerland. 